“¿Sabe una cosa don Videla?" Construcción de consenso, acción cívica y nacionalismo territorial en la revista Cono Sur, 1978-1982

Gabriel Carrizo

páginas / año 13 - n³1 Enero - Abril / ISSN 1851-992X/ 2021

http://revistapaginas.unr.edu.ar/index.php/RevPaginas

DOI: http://dx.doi.org/10.35305/rp.v12i30.475

\title{
“¿Sabe una cosa don Videla?” \\ Construcción de consenso, acción cívica y nacionalismo territorial en la revista Cono Sur, 1978-1982 ${ }^{1}$
}

\author{
"Does Don Videla know anything?" \\ Building consensus, civic action and military discourse in a \\ magazine from southern Argentina, 1978-1982
}

\author{
Gabriel Carrizo \\ Universidad Nacional de la Patagonia San Juan Bosco; \\ Universidad Nacional de la Patagonia Austral; \\ Consejo Nacional de Investigaciones Científicas y Técnicas (Argentina) \\ gabo.carrizo@gmail.com
}

\begin{abstract}
Resumen
En este artículo analizaremos de qué manera la revista Cono Sur contribuyó a la construcción de consenso social en torno a la dictadura en la Patagonia. En el contexto del conflicto con Chile por el canal de Beagle surgió una publicación que, en nombre de la defensa de la soberanía en el sur argentino, promovió a través de sus páginas una imagen venerable de las Fuerzas Armadas. El trabajo mostrará que paralelamente a la expulsión y persecución de pobladores chilenos ordenadas por las autoridades militares, la revista colaboró en dar visibilidad y exaltar el trabajo territorial que las fuerzas armadas desarrollaban en la Patagonia, con la finalidad de buscar consensos en torno a los objetivos del régimen.
\end{abstract}

\section{Palabras Clave}

Consenso; acción cívica; nacionalismo territorial; dictadura; Patagonia.

\begin{abstract}
In this article we will analyze how the Cono Sur magazine contributed to building social consensus around the dictatorship in Patagonia. In the context of the conflict with Chile over the Beagle Channel, a publication emerged that, in the name of defending sovereignty in
\end{abstract}

\footnotetext{
${ }^{1}$ A Ercilia del Carmen Ruiz
}

Esta obra está sujeta a la Licencia Reconocimiento-NoComercial-CompartirIgual 4.0 Internacional de Creative Commons. http://creativecommons.org/licenses/by-nc-sa/4.0/ 


\section{Gabriel Carrizo}

southern Argentina, promoted through its pages a venerable image of the armed forces. The work will show that in parallel to the expulsion and persecution of Chilean settlers ordered by the military authorities, the magazine collaborated in giving visibility and exalting the territorial work that the armed forces carried out in Patagonia, in order to seek consensus around the objectives of the regime.

\section{Keywords}

Consensus; civic action; territorial nationalism; dictatorship; Patagonia.

\section{Introducción}

En los últimos años distintos estudios que conforman el campo de la historia reciente en la Argentina vienen revelando que el régimen dictatorial instaurado en 1976 no se sostuvo exclusivamente apelando a mecanismos represivos, sino que buscó y obtuvo importantes niveles de consentimiento por parte de no pocos sectores de la población (Corradi, 1996; Lvovich, 2007 y 2018; Roldán, 2007; Luciani, 2009; González Canosa, 2011; Águila, 2015, 2019; Seitz, 2015; Catoira, 2018). Inscribiéndonos en esta serie de trabajos que plantearon la importancia de atender no solamente la dimensión represiva de la última dictadura militar, sino también conocer las estrategias que se implementaron para la búsqueda de legitimidad, en este artículo buscamos dar a conocer un aporte desde un estudio local al análisis de la construcción social del consenso hacia la Junta Militar, a partir del abordaje de una prensa regional que se fundó al calor del conflicto con Chile por el Canal del Beagle en 1978.

Nuestro objeto de estudio es la revista Cono Sur ${ }^{2}$, una publicación concebida para consolidar la defensa de los derechos argentinos sobre los territorios en disputa con Chile, reactivando el ideario propio de un nacionalismo territorial ${ }^{3}$ que buscaba no

\footnotetext{
2 Un primer abordaje se publicó en (Carrizo, 2019a). Agradezco los minuciosos comentarios de los evaluadores externos, que contribuyeron a la re escritura de este artículo. Este análisis es deudor de las lecturas, comentarios y sugerencias de Marisa Moroni, Brígida Baeza y Francisco Camino Vela. Este trabajo se enmarca en las discusiones e intercambios que se desarrollan en la Red de Estudios Sociohistóricos sobre la Democracia (RESHIDE).

${ }^{3}$ Cuando hablamos de "nacionalismo territorial" nos referimos a la forma de imaginar la relación entre territorio y nación, que fue construida por el los nacionalistas a lo largo del siglo XX. Desde esta concepción se entiende al territorio como elemento crucial y definitorio de la identidad nacional, al punto tal de generar una "obsesión territorial" que se manifiesta en una "hiper sensibilización" de las cuestiones limítrofes, en una expansión cartográfica y en la elaboración de un enemigo que atenta contra la integridad de la nación. Ante las dificultades de apelar a elementos culturales para definir una nación a fines del siglo XIX, los nacionalistas argentinos recurrieron al territorio, sobre todo luego de la década del '30, contando con el decidido apoyo de la corporación castrense. Para un estudio que reconstruye históricamente las transformaciones del nacionalismo argentino y su percepción del territorio, véase Bohoslavsky (2006). Durante la última dictadura, la geografía conservadora argentina consolidó y legitimó el "nacionalismo territorial" como forma de concientizar acerca de la necesidad de cuidar ciertos espacios para asegurar y preservar la identidad nacional (Cecchetto, 2016).
} 


\section{“¿Sabe una cosa don Videla?” Construcción de consenso, acción cívica y nacionalismo territorial en la revista Cono Sur, 1978-1982}

solamente cohesionar a la población, sino también obtener su apoyo. Promovió la adhesión al régimen desde la región patagónica, dándole una creciente importancia a la voz militar en sus páginas para hacerla llegar a cada rincón de la región, tratando de captar la aprobación de la opinión pública a través de una "conveniente" difusión de los actos de gobierno. Consideramos que la revista se instituyó como un lugar de enunciación desde el cual se desplegaron una serie de "núcleos de sentido" (Risler, 2019: 183), con la pretensión de moldear las actitudes, comportamientos y valoraciones que pudieran contribuir a la conformación de una imagen positiva (Seitz, 2015). Nos enfocaremos en lo que se ha denominado "proceso de organización del consenso" (Calvo Vicente, 1995), para conocer de qué manera se buscó construir una base social de apoyo al régimen militar.

Por otro lado, la historiografía argentina viene resaltando la importancia de incorporar abordajes locales de la historia reciente, dado que aportan una complejidad a partir de una serie de "tramas reticulares conectadas que conforman una determinada configuración sociohistórica que pueden resultar muy diferentes a los relatos hegemónicos" (Servetto, 2019: 12). Es en los diversos estudios de caso en escala local / regional donde se pueden observar una multiplicidad de actitudes sociales, su variabilidad temporal y heterogeneidad (Águila, 2015; Lvovich, 2018). De allí que teniendo en cuenta estos planteos, realizaremos nuestro análisis en el período comprendido entre el conflicto con Chile por el Canal de Beagle (diciembre de 1978) y el inicio del conflicto por Malvinas (abril de 1982). Coyuntura en la cual podemos observar en la revista una mayor sensibilidad ante lo que se consideraba una débil defensa de la soberanía en un territorio como el patagónico, el cual históricamente experimentaba la apetencia extranjera. Y por otra parte, el estudio de la prensa regional durante esos años constituye una vía privilegiada para observar en escala local la búsqueda de consenso hacia la dictadura en un espacio como el patagónico. Lugar donde la presencia de las Fuerzas Armadas contaban con una histórica legitimidad, cuestión que nos puede proporcionar algunos matices en torno a la comprensión de las actitudes de adhesión al régimen (Luciani, 2009; Lorenz, 2010).

En cuanto a la contribución específica de esta investigación, podemos mencionar en primer lugar que nos permitirá obtener conocimiento sobre el posicionamiento que adoptó cierta prensa regional en aquel contexto. Al respecto, en el año 2001 el historiador Pablo Lacoste (2001) afirmaba que recién por aquellos años, se había comenzado a abordar de manera crítica el comportamiento que habían asumido distintos actores (entre ellos la prensa) con respecto al conflicto con Chile por el Canal de Beagle. Si bien conocemos la existencia de estudios de los diarios y revistas más importantes de circulación nacional que en ese período buscaron obtener el acompañamiento de la población con respecto a los objetivos del régimen (Franco, 2002; Borrelli, 2011; Máspoli, 2014; Iturralde, 2017), poco se sabe aún de los medios de comunicación patagónicos en esta particular coyuntura, a excepción de la investigaciones dedicadas al diario Río Negro (Azcoitia, 2014), Crónica y El Patagónico de Comodoro Rivadavia (Olivares, 2015). Asimismo, este análisis de una 


\section{Gabriel Carrizo}

revista como Cono Sur busca complementar aquellos abordajes que han ampliado los conocimientos sobre la búsqueda de consenso de la Junta militar durante el conflicto con Chile por el Canal de Beagle a partir de la consulta de archivos militares ${ }^{4}$.

En cuanto a la organización de este artículo, en la primera sección nos ocuparemos de desarrollar en qué consistió el conflicto con Chile, las derivaciones del mismo sobre todo en relación al control y posterior expulsión de pobladores chilenos de Comodoro Rivadavia, y la creación de un medio de comunicación dispuesto a alinearse a los objetivos del régimen en nombre de la defensa de la soberanía nacional. En segundo lugar, analizaremos de qué manera la revista implementó una serie de estrategias discursivas que apuntaban, por un lado, a interpelar a jóvenes conscriptos y sus madres; y por otro lado, a visibilizar la acción cívica implementada por las Fuerzas Armadas en la región. En la tercera parte, abordaremos de qué manera se plasmaron en la revista distintas referencias al denominado nacionalismo territorial. En la última sección presentaremos algunas conclusiones del trabajo.

\section{El conflicto del Beagle y el surgimiento de la revista Cono Sur}

Como hemos adelantado, en esta primera sección caracterizaremos el contexto histórico a partir del cual surgió la revista Cono Sur en Comodoro Rivadavia a fines de 1978, y para ello es necesario presentar previamente las razones que llevaron a la Argentina a un potencial enfrentamiento bélico con Chile. Esta beligerancia se inició cuando, luego de varios intentos por solucionar por la vía diplomática los temas pendientes en materia fronteriza, Chile acudió en 1967 al sistema de arbitraje conforme a las facultades que le otorgaban los denominados Pactos de Mayo de 1902. Ese acuerdo rubricado a principios del siglo XX había establecido un sistema de solución de cuestiones fronterizas pendientes bajo el cual ambos países se comprometieron a aceptar los fallos, los cuales debían ser considerados inapelables y obligatorios para las partes. Luego de diferencias y desacuerdos en materia de política exterior en el transcurso del gobierno de Juan Carlos Onganía, el 22 de julio de 1971 durante el gobierno de Alejandro Agustín Lanusse se firmó el tratado por el cual la cuestión del Beagle se sometió a arbitraje internacional. Una vez conocida la resolución tomada por una Corte Arbitral conformada por especialistas, la misma fue emitida para las partes el 2 de mayo de 1977 por la Corona Británica mediante un laudo que dictaminó que las islas en disputa (Picton, Nueva y Lenox) pertenecían a Chile. El 25 de enero de 1978, y tras varios meses de silencio que contribuyeron al crecimiento de un clima hostil hacia Chile a partir de diversas manifestaciones

\footnotetext{
${ }^{4}$ A partir de la consulta de documentos producidos por el Estado Mayor General del Ejército y Actas de la Secretaría General de la Junta Militar, alojados en el Servicio Histórico del Ejército se pudo conocer el desarrollo de programas oficiales destinados a la construcción de consenso (Risler \& Schenquer, 2019).
} 


\section{“¿Sabe una cosa don Videla?” Construcción de consenso, acción cívica y nacionalismo territorial en la revista Cono Sur, 1978-1982}

difundidas en los medios de prensa, el Poder Ejecutivo Nacional declaró nulo el laudo arbitral.

A partir de allí, la defensa de la soberanía (considerada ahora lesionada), se transformó en un imperativo, a tal punto que la guerra pasó a transformarse en un hecho posible para los dos países. El historiador chileno Gonzalo Aravena Hermosilla (2009) rescató las memorias de los soldados que fueron movilizados por las Fuerzas Armadas chilenas al sur del país, los cuales recibieron instrucción militar y un discurso nacionalista dada la posibilidad cierta de entrar en combate. Estos acontecimientos eran vividos por los habitantes de Comodoro Rivadavia con suma preocupación, sobre todo por la importante migración chilena que se asentó a lo largo de la historia, siendo punto de encuentro entre familias que habían sido separadas por motivos económicos, o bien como consecuencia de la persecución política (Baeza, 2007; Torres, 2008/2009). Los dos períodos de mayor afluencia de chilenos coinciden con una etapa donde fue necesaria la llegada de un importante número de trabajadores a la ciudad petrolera: durante la denominada Gobernación Militar $^{5}$ (1944-1955) y el llamado Boom Petrolero (1958 - 1963), siendo este último movimiento migratorio el que ameritará la publicación de una serie de alertas acerca del "peligro chileno"6. Nos referimos al texto escrito por Eduardo Gallegos denominado Invasión por el sur, el cual contribuyó a la solidificación de una perdurable estigmatización de la migración chilena a principios de los '70. Dicha publicación emergía con el objetivo de "estudiar su presencia, controlarla dentro de los límites aceptables para la tranquilidad y el crecimiento ordenado de nuestra Patagonia Argentina" (1971: 11). Allí se denunciaba que con el último Boom Petrolero que había experimentado la ciudad entre 1958 y 1963 (el cual era el resultado de la firma de 13 contratos petroleros con compañías privadas, una nueva ley de hidrocarburos y un nuevo estatuto orgánico de YPF) se había incrementado la llegada de extranjeros en busca de trabajo (Vázquez, 2019). Para Gallegos este período fue el causante de una "invasión silenciosa" (la chilena) que alteró tanto la estructura como la dinámica de la comunidad, dado que para el autor se había constatado una explosión demográfica a partir de la conformación de innumerables asentamientos informales.

Es decir que cuando la Junta Militar endureció el conflicto con Chile por el canal de Beagle, pasando a posiciones directamente xenófobas que alertaban acerca del peligro que significaba la no integración a la comunidad nacional de los chilenos, no

\footnotetext{
${ }^{5}$ La Gobernación Militar de Comodoro Rivadavia fue una jurisdicción creada por el gobierno nacional en 1944, conformada por la zona norte de Santa Cruz y la zona sur de Chubut, a lo largo de la cuenca del Golfo San Jorge. El origen de la misma se debe a la necesidad de controlar militarmente un espacio en la Patagonia central considerado estratégico en términos geopolíticos, dada la intensa explotación hidrocarburífera desarrollada en la zona. Véase Carrizo (2016).

${ }^{6}$ Sebastián Barros (2019) ha afirmado que a los inmigrantes que han arribado a Comodoro Rivadavia en distintas oleadas, se los "humilla y festeja a la vez", para hacer referencia a una valoración del fenómeno en términos contradictorios: si bien contribuyen al desarrollo de la ciudad a partir de la mano de obra aportada fundamentalmente a la construcción de edificios públicos o en el ámbito petrolero, a la vez son vistos como generadores de innumerables problemas sociales.
} 


\section{Gabriel Carrizo}

hacía más que reforzar una mirada largamente extendida en la Patagonia en textos como el de Eduardo Gallegos. De allí que la percepción de Chile como "país expansionista" y "sustractor de territorio" eran núcleos de sentido que habían sido construidos y difundidos por referentes del nacionalismo territorial por lo menos desde la década del '30, que en esa coyuntura fueron amplificados por diversos medios de comunicación, y "como resultado de este proceso se creó un clima claramente adverso a la aceptación del laudo arbitral" (Lacoste, 2003: 379). La consecuencia posterior fue que el conflicto de 1977 y 1978 llevó a la Argentina a ir a contramano de la tradición de su diplomacia, que se había caracterizado hasta allí por la aceptación del resultado de los arbitrajes y el pacifismo.

El conflicto con Chile evidenció una vez más para las autoridades que la Argentina debía defender su soberanía en territorio patagónico, razón por la cual se publicaron varios ensayos escritos desde el ámbito castrense que buscaron fortalecer los argumentos del gobierno argentino. El tono bélico de las publicaciones quedan de manifiesto en la siguiente advertencia que se realizaba en 1980, una vez superado el momento de mayor tensión: "Y si los hechos volvieran a repetirse, si persiste la tozudez chilena, a la instancia agotada, seguiría una única y trágica opción: imponer el derecho mediante el diálogo de las armas" (Guglialmelli, 1980: 178). El mismo autor hacía un llamamiento a la población a no aminorar el clima de beligerancia con el vecino país, dada la vulnerabilidad de la Patagonia argentina: "De ahí la necesidad de movilizar con premura las energías morales, espirituales de la Nación; de potenciar sin fisuras sectoriales o espaciales los cuatro componentes del mencionado poder nacional: político, económico, militar y psicosocial" (Guglialmelli, 1980: 178).

La defensa de la soberanía exigía adoptar acciones ejecutivas por tratarse de un grave problema geopolítico, las cuales afectaron la vida cotidiana de los habitantes ubicados en las zonas limítrofes de la Patagonia a partir de la presencia militar. Por ejemplo, la localidad de Trevelin (noroeste de Chubut), fue incluida dentro de las denominadas Áreas de Seguridad de Frontera, y se promovió allí la radicación y asentamiento de pobladores argentinos como una forma de protección ante el "expansionismo chileno" (Baeza, 2009). En la localidad de Río Mayo (sudoeste de Chubut), se creó en 1980 el Regimiento 37 de Infantería a partir de los mismos objetivos. En otros casos se buscó fortalecer la identidad nacional con la distribución por todo el territorio de las repetidoras del canal LU 85 ubicado en la capital Río Gallegos $^{7}$. También a través del desarrollo de políticas culturales, como la concreción de un festival nacional de folklore en la ciudad de Pico Truncado (provincia de Santa Cruz), evento que recibió a figuras importantes de la cultura nacional ${ }^{8}$.

\footnotetext{
${ }^{7}$ Cono Sur, Comodoro Rivadavia, 01/03/1980, p. 36.

${ }^{8}$ Los artistas invitados al evento (Los Cantores del Alba, Zamba Quipildor, Luis Landriscina, entre otros), coincidían en apoyar la música nacional, oponiéndose a aquella que provenía del extranjero. En una entrevista, decía Landriscina: "Lo vergonzoso de todo esto es que nuestra gente, la juventud principalmente, se la pasa escuchando discos grabados en lengua extranjera, sin saber lo que están escuchando". Cono Sur, Comodoro Rivadavia, 01/11/1980, p. 14.
} 


\section{“¿Sabe una cosa don Videla?” Construcción de consenso, acción cívica y nacionalismo territorial en la revista Cono Sur, 1978-1982}

En el contexto dictatorial estas acciones se complementaron con otras. A partir de fuentes poco abordadas, como aquellas provenientes de los servicios de inteligencia que operaban en la provincia del Chubut en aquellos años ${ }^{9}$, podemos conocer qué medidas se aplicaron con respecto a la comunidad chilena en Comodoro Rivadavia en el contexto del conflicto por el Canal del Beagle. Podemos mencionar por ejemplo, la solicitud de informes sobre estudiantes de nacionalidad chilena que concurrían a la Universidad como a establecimientos secundarios o listados de chilenos que trabajaban en servicios considerados esenciales para la provincia o la expulsión de la ciudad de alrededor de 230 chilenos. En el contexto del conflicto limítrofe, estos años significaron momentos de extrema tensión para la comunidad chilena en Comodoro Rivadavia, cuestión que los obligó a invisibilizar todo tipo de manifestaciones culturales (Torres, 2008/2009).

Retomando nuestra exposición inicial, lo que queremos señalar es que estas acciones de coerción ejercidas de forma arbitraria contra todo aquel habitante chileno en Comodoro Rivadavia (previo proceso de estigmatización como el mostrado a través de la obra de Gallegos), fueron realizadas de manera simultánea a la búsqueda de consenso a partir de la publicación de una revista que estuviera al servicio de la defensa de la soberanía. Es decir, Cono Sur se constituyó en un medio de comunicación a partir del cual la dictadura promovió una serie de núcleos de sentido necesarias para construir un marco de legitimidad y apoyo interno frente a la política exterior en el contexto del conflicto con Chile. Es por ello que su aparición en diciembre de 1978 coincidió con la puesta en marcha de la denominada "Operación Soberanía”, mediante la cual se dispuso la movilización de tropas al sur. Además la revista fue una estrategia más, que se sumó a otras que fueron implementadas por el régimen en esa coyuntura, que tuvieron como objetivo consolidar la conciencia territorial (Rodríguez, 2014). La más importante de ellas sin dudas fue el Operativo impulsado en 1979 mediante un convenio entre el Ministerio de Cultura y Educación y la Gendarmería Nacional, que se denominó “¡Argentinos! marchemos hacia las fronteras”. El mismo tenía por objetivo intervenir en áreas de frontera consideradas históricamente desatendidas, y caracterizadas por estar pobladas de extranjeros, con altos índices de pobreza, con falta de educación y atención sanitaria. El operativo consistió en trasladar a esas zonas a estudiantes del último año de la secundaria, para realizar tareas de ayuda a docentes y alumnos. Además se donaban materiales, se presentaban espectáculos artísticos junto a personalidades conocidas, y se proyectaban películas nacionales (Rodríguez, 2010).

Si bien no hemos encontrado documentación que pruebe que Cono Sur fue solventado con recursos estatales, si podemos afirmar que fue una publicación alentada y celebrada por las autoridades de aquél período. También es posible inferir que se enmarcó en una serie de acciones comunicacionales que se desarrollaron bajo la promoción de la Secretaría de Información Pública de

\footnotetext{
${ }^{9}$ Caja 1978. Colección SICH APM SDDHH Chubut.
} 


\section{Gabriel Carrizo}

Presidencia (SIP), órgano de control que dispuso la dictadura no sólo para monitorear a los medios de comunicación, sino también para difundir información y propaganda acorde con sus objetivos. El denominado Plan Teatro de Operaciones Oeste (TOO) estuvo conformado por operaciones psicológicas proyectadas entre 1981 y 1982 a partir del conflicto entre Chile y Argentina por el Canal del Beagle, las cuales eran necesarias para gestionar toda tensión política y social que se generó ante la inminencia de la guerra. Este Plan se enmarcó en el denominado "Principal Elemento de Comunicación Social” (PELCOS), que había sido creado en 1979 por la Junta Militar, para desplegar un planificado y coordinado sistema de comunicación que fuera capaz de movilizar a diferentes públicos. Desde su inicio se le otorgó prioridad a la temática de la soberanía argentina, la cual debía interpelar a la opinión pública a través de diversos procedimientos comunicacionales. El Plan, que indicaba una serie de fases a partir de las cuales se desplegaría la acción psicológica, tenía previsto como uno de sus objetivos el de crear en el entorno familiar del personal militar la predisposición a la entrega de uno de sus miembros ante el posible conflicto bélico (Risler \& Shenquer, 2019).

Estos núcleos de sentido (que analizaremos en la siguiente sección), son los que poblaron las páginas de Cono Sur, una publicación novedosa para el ámbito de los medios de comunicación en el sur del país. Se trataba de una revista editada en Comodoro Rivadavia con salida mensual que informaba, mediante una cobertura de carácter regional, sobre la realidad patagónica ${ }^{10}$. Con alrededor de 30 páginas, abundantes fotografías, corresponsales en varios pueblos patagónicos, y un papel de calidad, Cono Sur se presentó como una "Revista de Comodoro Rivadavia por la Patagonia y para el país". Como se ha indicado en un estudio acerca de su construcción discursiva, se autodefinió como una publicación nacionalista, contribuyendo a la conformación de un imaginario social legitimando determinadas tipificaciones y prejuicios dirigidos sobre todo a la migración limítrofe. No solamente se la responsabilizaba de las persistentes crisis económicas, sino que además asumía como hipótesis la apropiación extranjera del territorio a través de diversas acciones premeditadas, ante la preocupante pasividad del estado nacional (Bayón, 2012). Ante la falta de reafirmación de la soberanía en el sur, Cono Sur demandó sistemáticamente a la Junta Militar medidas tendientes a generar conciencia acerca de las diversas problemáticas de la Patagonia. En particular daba cuenta de las diversas actividades (políticas, económicas, sociales, culturales, militares) de las provincias del Chubut, Santa Cruz y Tierra del Fuego, buscando generar conciencia acerca de las diversas problemáticas, a la espera de que "otros argentinos (...) vengan a reforzar, con su presencia, nuestra frontera sur"11. Quien

\footnotetext{
10 La revista contaba con una mesa de redacción conformada por siete periodistas, una administradora, un Departamento Publicitario, y tres reporteros gráficos. Luego de la tapa se ubicaba la nota editorial donde se expresaba su posición institucional ante temas generalmente vinculados a la defensa de la soberanía. Para 1982 la revista contaba con corresponsales en Buenos Aires, Trelew, Puerto Deseado, Río Gallegos, Ushuaia, Río Grande, Los Antiguos, Mar del Plata y Pico Truncado.

${ }^{11}$ Cono Sur, Comodoro Rivadavia, 01/10/1979, p. 3
} 


\section{“¿Sabe una cosa don Videla?” Construcción de consenso, acción cívica y nacionalismo territorial en la revista Cono Sur, 1978-1982}

fuera director y editor de la revista, Emilio José Said, en una entrevista realizada en 2015, se refirió de esta manera con respecto al contexto en el que surgió la revista:

"era un momento político muy especial, de conflicto por los límites con Chile. Estaba muy caliente el ambiente, muy peligroso. Quisimos ser una voz más en apoyo a lo que nos pertenece (...) fuimos a ver al intendente [Mario Adalberto] Provedo. Le fascinó la idea y nos hizo una resolución. Empezamos a grabar, a viajar, enseguida todo el mundo nos apoyó".

Este apoyo que recibió Said lo convirtió en uno de los tantos "comunicadores llave", es decir, aquellos periodistas o comunicadores que "actuaron de acuerdo a los lineamientos planteados por el régimen en lo referente a la difusión de una elaborada y cuidada información y propaganda" (Risler: 2018: 117). De hecho, en aquella entrevista de 2015 se los presenta de la siguiente manera: "Elsa y Emilio dedicaron su vida al trabajo con una fuerte convicción nacionalista", pues fueron "fieles defensores de la soberanía nacional"12. Definitivamente lo territorial fue parte de la agenda de Cono Sur, erigiéndose en defensor de la soberanía ante cualquier amenaza o agresión. De allí por ejemplo las constantes denuncias acerca de la imposibilidad de acceder a Tierra del Fuego sin transitar por territorio chileno. Esto implicaba que no se podía cruzar el estrecho de Magallanes sin pasar por el control de carabineros, debiendo pagar tarifas de aduana con moneda chilena. Al respecto publicaba la revista la siguiente reflexión: "Es como si para ir a otra de nuestras habitaciones debiéramos pedir permiso al vecino para pasar por su patio". En la misma nota se denunciaba que autoridades chilenas no permitieron el paso de camiones argentinos por considerar que trasladaba "material estratégico": "con esa acción, se ha visto avasallada una vez más nuestra soberanía en tierra sureña"13.

En la siguiente sección nos detendremos en dos estrategias puestas en práctica por Cono Sur para la construcción de consenso. En primer lugar, veremos algunas notas representativas de la línea editorial de la revista que interpelaban tanto a los jóvenes como a las madres para afrontar las dolorosas consecuencias de un posible enfrentamiento bélico. En segundo lugar, analizaremos la creciente voz que fueron adquiriendo las fuerzas armadas en las páginas, dando cuenta de una activa acción cívica en colaboración con las denominadas fuerzas vivas de la Patagonia.

\section{La dictadura y la búsqueda de consenso a través de Cono Sur}

Cono Sur se constituyó como un medio de prensa que dio cobertura y visibilizó la acción cívica desarrollada por las Fuerzas Armadas, aún en los pueblos más recónditos de la Patagonia. Desde sus páginas subrayaba que la defensa de la

\footnotetext{
12 "Elsa" era Antonia Elsa Zamorín, esposa de Said y formaba parte de la revista como administradora. Cono Sur, Comodoro Rivadavia, 01/03-04/2015, p. 8.

${ }^{13}$ Cono Sur, Comodoro Rivadavia, 01/03/1980, p. 35.
} 


\section{Gabriel Carrizo}

soberanía era un deber ineludible de todo argentino y argentina de bien, interpelando en distintas ocasiones a las mujeres en tanto madres de conscriptos ${ }^{14}$. Por ejemplo, en una columna que formaba parte de la estructura permanente de la revista, podemos advertir las implicancias de estas palabras. En este caso se trataba de una "carta abierta" dirigida a la madre de un soldado cuyo destino obligado había sido la ciudad de Río Gallegos. La periodista afirmaba haberla escuchado de manera casual en la Dirección de Turismo de dicha localidad, en donde

\footnotetext{
"con gesto despectivo se lamentaba de que su hijo hubiera tenido la 'mala suerte' de tener que hacer el servicio militar tan lejos y en un lugar 'tan feo'. (...) Pero lo que me molesta, señora, es que usted (como madre) no valore el aporte que hace ese hijo suyo con su presencia en nuestra Patagonia, región que es (por si no lo sabe) una de las más ricas del país en recursos naturales".
}

No solamente le recordaba que el gas con el que calefaccionaba su casa provenía de la Patagonia, al igual que alguna prenda (por ser derivada de la lana), la nafta e inclusive el quita esmalte (por ser derivados del petróleo); sino que además le señalaba que su hijo cumplía con su deber de custodiar una región que estaba siendo amenazada. En este sentido, la revista a través de sus páginas erigía a los jóvenes conscriptos en verdaderos protagonistas de la coyuntura que vivía el país. Por ejemplo, se publicaban las felicitaciones que le dedicaban los militares de alto rango a aquellos soldados "de apenas 18 años que habían brindado un ejemplo al país y a aquellos que aún no encontraron su identidad con la verdadera nación"15. Por supuesto ese momento histórico sin dudas se refería a la posibilidad de entrar en combate: "estos gurises de la Patria que, haciendo honor a las más viejas tradiciones militares argentinas acababan de pasar rumbo al puesto que la historia les marcó, para que nadie venga a discutirnos un centímetro más de suelo patrio o a poner en duda nunca más nuestra soberanía"16.

En otras crónicas que se publicaban, como por ejemplo en una de las primeras columnas publicadas en la revista firmada por "El vago Patagonia", se invitaba al lector a manifestar su apoyo a jóvenes conscriptos que desfilaban por el centro de la ciudad. Las narraciones solían estar cargadas de emotividad, y buscaban la identificación del lector con los soldados que se alistaban para una posible guerra, apelando a emociones como "orgullo" y "alegría”. Además esos jóvenes conscriptos eran retratados como "serios", "responsables", "decididos" y sobre todo "felices". También se buscaba generar unanimidad en la adhesión, de allí que se resaltaba que eran "muchos los que se paraban y los saludaban"; o "todos nos pusimos de pie y brindamos por los pibes"; o refiriéndose a Jorge Rafael Videla, "usted siga como hasta ahora...No les afloje ni un tranco de pollo, que en esta todos estamos con usted, $y$, si es necesario, ya sabe dónde encontrarnos, no lo dude un solo instante". El texto

\footnotetext{
${ }^{14}$ Cono Sur, Comodoro Rivadavia, 01/10/1979, p. 8.

${ }^{15}$ Cono Sur, Comodoro Rivadavia, 01/06/1979, p. 35.

16 Cono Sur, Comodoro Rivadavia, 01/01/1979, p. 13.
} 


\section{“¿Sabe una cosa don Videla?” Construcción de consenso, acción cívica y nacionalismo territorial en la revista Cono Sur, 1978-1982}

concluía con una demanda dirigida a Videla, un reclamo que partía desde un lugar de compromiso e identificación con los objetivos de la Junta Militar:

“ ¿sabe una cosa don Videla? (...) cuando todo pase, cuando todo vuelva a la normalidad, cuando no queden dudas en el mundo, y lo nuestro sea lo nuestro y niente de piu... chimeneas, Don Videla; fábricas, escuelas, pueblos y... argentinos... Este vago piensa que es la mejor forma de hacer que la soberanía no vuelva a ser discutida en este sur tan olvidado, tan grande, tan rico y tan argentino"17.

Además de estas interpelaciones Cono Sur ofreció sus páginas para la visibilización de las diversas actividades que las Fuerzas Armadas brindaban a la comunidad. Las mismas se enmarcaban en lineamientos específicos de la denominada "Acción Cívica" (de aquí en adelante AC), mediante la cual las Fuerzas Armadas debían presentarse ante los sectores potencialmente revolucionarios de la población como interesadas en mejorar las condiciones y la calidad de vida de los habitantes en los barrios (Divinzenso, 2016 y 2017; Risler, 2018; Zapata, 2018). Este involucramiento con las comunidades a través de la ejecución de obras prioritarias no era algo nuevo en la Patagonia, dado que desde principios del siglo XX el Ejército estaba asociado a su desarrollo. Los planes de AC eran parte de los programas de ayuda militar que brindaba Estados Unidos a los ejércitos latinoamericanos, y consistía en el uso de las fuerzas militares locales en proyectos de utilidad para la población, sobre todo porque se consideraba que el enemigo interno sería exitoso si lograba el apoyo de la misma (Risler, 2018). Si bien esta renovación doctrinaria de las Fuerzas Armadas en la Argentina comienza a experimentarse luego de 1955, se formalizará recién en 1963 a través de Programas específicos de Asistencia Militar.

En primer lugar, mediante la AC se debía mostrar la articulación entre distintos actores en defensa de la soberanía, reforzando esa unanimidad en la adhesión a los objetivos de la Junta Militar. Dado que había que consolidar la imagen de las fuerzas castrenses ante la sociedad, se necesitaba de un medio de prensa que diera cobertura y visibilice tanto su accionar materializado aún en los pueblos más recónditos de la Patagonia, como la activa y estrecha colaboración con la sociedad civil. De allí que a través de la revista podemos observar a la familia católica comodorense (Vicente, 2018) participando junto a las autoridades provinciales y municipales en cada acto patrio desarrollado en el interior de la provincia del Chubut, cuyos miembros se vinculaban con los funcionarios civiles: las distintas fuerzas armadas, el Obispo Argimiro Daniel Moure, el Director del Liceo Militar General Roca, el rector de la Universidad Nacional de la Patagonia San Juan Bosco presbítero Norberto Sorrentino y la Asociación de Reservistas.

En el caso de la recientemente creada Universidad Nacional de la Patagonia San Juan Bosco, esta institución asumió decididamente un rol importante de defensa de la soberanía, el cual quedó plasmado en el discurso de su primer rector el presbítero

\footnotetext{
17 Cono Sur, Comodoro Rivadavia, 01/01/1979, p. 13.
} 


\section{Gabriel Carrizo}

Norberto Sorrentino ${ }^{18}$. Esto se tradujo en acciones específicas, como la creación de la cátedra de geopolítica Francisco P. Moreno en junio de 1980, a partir de una demanda del Círculo de Egresados de la Escuela de Defensa Nacional (Carrizo, 2019b). El curso, que contó con el asesoramiento del teniente coronel Justo Eriberto Aubel y que se presentaba como una formación de posgrado inédita para la región, se proponía replantear la visión del espacio geopolítico. Este tipo de formación se vinculaba a los denominados "Cursos Regionales de Defensa Nacional”, en donde las fuerzas armadas articulaban acciones con las Universidades (Rodríguez, 2015).

En segundo lugar, esta AC se caracterizaba por la ejecución de tareas concretas, de las que pudieran obtenerse resultados rápidos para su posterior difusión en la revista. De allí que en base a lo mostrado por algunas investigaciones dedicadas a analizar la AC a través de reglamentaciones y documentos elaborados por las fuerzas armadas (Divinzenso, 2016 y 2017), se buscaba que las obras para la comunidad fueran de corta duración. Cono Sur publicaba con detalle de qué se trataban estas acciones que iban desde la nivelación de calles, construcción de zanjas y desagües, control sanitario y odontológico, hasta la reparación de escuelas. En una amplia entrevista realizada al jefe de la unidad militar de la localidad de Puerto Deseado (Santa Cruz), se afirmaba: "aquí el esfuerzo es realmente mancomunado entre las autoridades, civiles, militares, fuerzas de seguridad, clubes, entidades y población en general. Yo diría que donde se está 'al servicio' de algo, y no 'para servirse', es el lugar donde pueden sentarse las bases necesarias para que aquellas zonas privilegiadas se materialicen como reales polos de desarrollo"19. Aquí se expresaba claramente ese "ethos institucional antipolítico" que tanto caracterizó a la dictadura y sus cuestionamientos a la política civil, a la cual se le asignaba estar siempre al servicio de intereses egoístas, la corrupción y la demagogia (Canelo, 2016).

Por su parte la Compañía de Comunicaciones 9 asentada en Comodoro Rivadavia realizó un "operativo de control de población, sanitario y actividades de acción cívica" en el barrio Laprida, con la participación de 200 efectivos. De las tareas realizadas en el barrio también participaron efectivos policiales, personal de la Municipalidad y de Yacimientos Petrolíferos Fiscales. Cono Sur concluía que "al final se sirvió chocolate con facturas a los niños, y la Banda del Regimiento de Infantería 8 ejecutó la Retreta del Desierto. Fue un acto más a los que nos tiene acostumbrado el Ejército en la labor comunitaria que desarrolla en el sur argentino" 20 .

En tercer lugar, esa AC debía mostrar a los militares con rasgos que pudieran generar cierta empatía. Una de las estrategias implementadas por la prensa afín al régimen para humanizar a los gobernantes consistía en la publicación de notas de color que resaltaran un costado poco conocido. Con el objetivo de generar cierta

\footnotetext{
18 Discurso del Sr. Rector Rvdo. Padre Lic. Norberto Sorrentino, con motivo de la asunción de su cargo, Comodoro Rivadavia, 19 de marzo de 1980, Universidad Nacional de la Patagonia San Juan Bosco, pp. 6-7.

${ }^{19}$ Cono Sur, Comodoro Rivadavia, 01/03/1980, p. 88.

20 Cono Sur, Comodoro Rivadavia, 01/10/1979, p. 36.
} 


\title{
“¿Sabe una cosa don Videla?” Construcción de consenso, acción cívica y nacionalismo territorial en la revista Cono Sur, 1978-1982
}

identificación de la población civil hacia los militares, se visibilizaron muestras de afecto, las cuales eran muy realzadas, sobre todo aquellas que provenían de altas autoridades:

\begin{abstract}
"Otro homenaje lo constituye ese gesto de dulzura casi inusual (por lo menos en público) del Gobernador [sic] del Chubut contraalmirante Ángel Lionel Martin, que en el acto del 20 aniversario de la escuela provincial $n^{\circ} 21$ Lewis Jones de Trelew, y en ese gesto, en esa mirada del mandatario provincial hay todo un mensaje a la niñez, como pidiéndole la entereza, patriotismo y arraigo que de ellos necesitará la Patagonia"21.
\end{abstract}

Los redactores de la revista estaban atentos ante cualquier expresión de simpatía, y por más pequeña que fuera, en algunos casos originó una extensa nota. Otro ejemplo que podemos aportar en este sentido, fue en ocasión del recibimiento que le ofreció el gobernador de Chubut al ministro del Interior general Eduardo Albano Harguindeguy. Al comentar la fotografía que daba cuenta de aquel encuentro, una periodista escribió que el alto funcionario de la dictadura llegaba a la provincia "con su amplia sonrisa y ese gesto amistoso tan pocas veces observado en él”22.

En cuarto lugar, la AC se desplegó por el interior profundo del territorio patagónico, considerando a las instituciones educativas como ámbito privilegiado de intervención. En este sentido Cono Sur apeló a realzar acciones que daban cuenta de un Ejército que, además de colaborar "desinteresadamente" con las distintas comunidades, también podía ser una institución que bregaba por la inclusión educativa. Además, la participación de altas autoridades militares en actos escolares eran la ocasión para incentivar la inserción de los niños en la sociabilidad militar, algo que no era novedoso en la historia de las Fuerzas Armadas en la Patagonia (Carrizo, 2013). Con motivo de la celebración del Día de la Patagonia el 20 de junio de 1980 en la ciudad de Esquel se afirmaba con respecto a los alumnos: "Ellos concurrieron a la jura de la bandera con la misma sensación de responsabilidad que los soldados. Son apenas niños de $4^{\circ}$ grado que ese día se sintieron capaces de defender nuestra enseña hasta morir"23. En otras ocasiones lo que se buscaba explícitamente era la adhesión unánime a los lineamientos del régimen. El gobernador de Santa Cruz Capitán de Fragata Juan Carlos Favergiotti, al inaugurar el ciclo lectivo de 1980 en la ciudad de Caleta Olivia (Santa Cruz) afirmó ante la comunidad educativa:

"Nuestros adolescentes han sido testigos contemporáneos de tiempos difíciles e inexplicables en un país como el nuestro. No dudamos que este testimonio tiene el valor de una lección severa que nuestra juventud no debe olvidar. Por ello, jóvenes, este proceso busca en ustedes legítimos herederos" 24 .

\footnotetext{
${ }^{21}$ Cono Sur, Comodoro Rivadavia, 01/10/1979, p. 3.

${ }^{22}$ Cono Sur, Comodoro Rivadavia, 01/02/1981, p. 7.

${ }^{23}$ Cono Sur, Comodoro Rivadavia, 01/06/1980, p. 29.

${ }^{24}$ Cono Sur, Comodoro Rivadavia, 01/03/1980, p. 42.
} 


\title{
Gabriel Carrizo
}

Cada uno de esos actos escolares ofrecía la oportunidad para brindar un mensaje destinado a la juventud, como por ejemplo, cuando el Director del Liceo Militar General Roca le recalcó a los nuevos egresados:

\begin{abstract}
"No os dejéis seducir por los que os prometen bienes materiales y por los que recurren al sexo, la violencia, las drogas, el secuestro, el crimen, el robo, el sabotaje, la destrucción, el enfrentamiento de sectores sociales en una supuesta lucha por la paz y la justicia, para enfatizar después: estad preparados para tomar las armas, si fuera necesario, para luchar y vencer a quienes ataquen nuestra soberanía, nuestra libertad o pretendan por la fuerza de la violencia, el temor y la propaganda, imponernos dogmas extraños, liberalistas (sic) o comunistas, materialistas y ateos"25.
\end{abstract}

Otra de las vías privilegiadas para ganar consenso era a través del apadrinamiento de instituciones educativas, sobre todo en aquellas localidades más alejadas de los centros urbanos, las cuales eran destacadas por la revista como "abandonadas" hasta la llegada de las Fuerzas Armadas. Estos eventos eran la ocasión especial para que cada fuerza que intervenía inscribiera su propia huella en las escuelas, haciendo uso de un pasado considerado heroico. Lo que demuestra que aún en los ámbitos más recónditos de la Patagonia, la dimensión propositiva de la dictadura para estimular la aceptación del régimen se hacía presente a través de inscripciones en el territorio de símbolos militares (Shenquer \& Cañada, 2020). Por ejemplo, la Policía Federal impuso su nombre a la escuela $n^{\circ} 71$ de Aldea Beleiro (Chubut), luego de haber invitado a los alumnos a un viaje con destino a Comodoro Rivadavia, en la cual no solamente pasearon sino que además disfrutaron de un festival artístico y recibieron atención médica de control ${ }^{26}$. Por su parte la Fuerza Aérea apadrinó a la escuela $\mathrm{n}^{\circ} 94$ de Lago Blanco (pequeño pueblo ubicado en Chubut a 30 kilómetros de la frontera con Chile), colocándole el nombre de Benjamín Matienzo, aquél militar considerado pionero de la aviación nacional. Cono Sur, luego de dar cobertura al acto afirmó:

\begin{abstract}
"Allí hay una única escuela, que atiende una también única maestra al frente de casi cincuenta alumnos. No hace mucho se incendió su puesto sanitario, que ahora presta servicios en una casa particular con medios tan precarios, como que los medicamentos existentes apenas son los alcanzados por la Asociación de Reservistas de Comodoro Rivadavia en una acción cívica reciente, que todos debieran imitar"27.
\end{abstract}

En estos actos podemos advertir la articulación entre distintos actores, en pos de ofrecer a la comunidad obras que buscaban una unánime adhesión. Al respecto tomaremos otro ejemplo ilustrativo, a partir de una nota que llevaba por título: “Alumnos con uniforme de soldado. ¡Por fin puedo escribirle a mi madre!”. Se trataba de una extensa narración periodística referida a la escuela ${ }^{\circ} 140$ que funcionaba

${ }^{25}$ Cono Sur, Comodoro Rivadavia, 01/10/1979, p. 46.

${ }^{26}$ Cono Sur, Comodoro Rivadavia, 01/07/1980, p. 52.

${ }^{27}$ Cono Sur, Comodoro Rivadavia, 01/10/1980, p. 38. 


\title{
“¿Sabe una cosa don Videla?” Construcción de consenso, acción cívica y nacionalismo territorial en la revista Cono Sur, 1978-1982
}

dentro del regimiento 25 de infantería de la localidad de Sarmiento, bajo la Dirección Nacional del Adulto. Cono Sur entrevistó a los soldados que hacían la conscripción y que concurrían a la escuela, la mayoría provenientes del interior de la provincia de Córdoba. Uno de ellos dijo:

\begin{abstract}
"Bueno, me enteré por unos compañeros que venían a la escuela, y le dije al encargado de batería si me podía mandar. Y aprendí un poquito bastante. Porque, la verdad, no sabía nada. Ahora sé leer, sumar, restar, multiplicar... Ya le pude escribir dos cartas a mi madre y una a mi tío, cuando antes tenía que pedir a mis amigos que escribieran en lugar mío. Y se ve que me entienden lo que escribo, porque me contestan".
\end{abstract}

Cono Sur retomó estos testimonios para exaltar que el paso de los jóvenes por el servicio militar permitía reparar de alguna manera cierta desigualdad social y educativa:

\begin{abstract}
"Todos, por un motivo u otro, fueron analfabetos; lo eran a medias, o no habían terminado la escuela primaria, vaya a saber por qué negligencia, o qué motivaciones insalvables de la vida. (...) Allí están, ahí conviven... Como los conscriptos de siempre... Juntos en un año plagado de anécdotas que de ahí en más contarán hasta el cansancio en la vida civil, como de ésta las relatan ahora. (...) Y también es posible que varios evoquen alguna vez lo que aquél al que preguntamos el recuerdo más lindo de su vida militar: 'Tantos... ¡qué sé yo! Por ejemplo. El de la escuela: saber leer y escribir'..."28.
\end{abstract}

Sin dudas que esta nota buscaba generar emotividad e identificación con tan loable tarea, y por ello no podía faltar de la cobertura periodística la finalización de los estudios de los conscriptos, lo que significaba haber alcanzado la alfabetización completa. Por ello, previa a la entrega de los certificados correspondientes, la supervisora provincial de la Dirección Nacional de Educación del Adulto Norma Lamberti de Portas destacó en la ceremonia una sentida y lejana ausencia: la madre de cada soldado. El momento de extrema sensibilidad debía tener un remate acorde: "Si me permiten (dijo) quisiera asumir la representación de quien en este momento mucho hubiera querido estar acompañando a cada uno de ustedes, dándoles un beso en nombre de ellas"29.

En la siguiente sección mostraremos de qué manera la revista promovió la defensa de la soberanía, adhiriendo al nacionalismo territorial, en un marco de legitimidad que otorgaban los estudios geopolíticos que se encontraban en expansión.

\footnotetext{
${ }^{28}$ Cono Sur, Comodoro Rivadavia, 01/10/1980, p. 31.

${ }^{29}$ Cono Sur, Comodoro Rivadavia, 01/11/1980, p. 22
} 


\title{
Gabriel Carrizo
}

\section{Cono Sur como expresión local del nacionalismo territorial}

Tanto las efemérides como los símbolos patrios ocupaban un lugar importante en la revista, realizándose una cobertura especial en cada conmemoración, sobre todo si se recibía la visita de algún alto funcionario nacional. De esa manera se constataba el grado de fervor patriótico en la Patagonia, el que siempre era necesario alentar para reafirmar unanimidad. De allí que la noticia acerca de un ciudadano argentino, hijo de una familia chilena, que el 9 de julio de 1981 vociferó "vivas al país vecino", ameritó una extensa nota que llevó por título "Justicia para el traidor". Este hecho no hacía más que confirmar las constantes denuncias de la penetración chilena en la Patagonia argentina, que ahora se reforzaba a través de la acción de los hijos de chilenos nacidos en suelo argentino:

\begin{abstract}
"Así permitimos que Chile fuera adentrándose en nuestro territorio no solamente en la faz material (caso estrecho de Magallanes y el Canal de Beagle por ejemplo) sino con esa peligrosa, invisible pero detectable actitud de aprovechar al máximo a los compatriotas radicados en nuestra tierra para tener un perfecto sincronizado y eficaz sistema de información permanente $\mathrm{y}$ gratuito" 30 .
\end{abstract}

Para Cono Sur tal actitud era incomprensible, dado que el acusado no solamente era empleado de YPF, sino que además había jurado lealtad a la bandera durante su paso por la conscripción. Por tales razones abogaba por hacer justicia frente al "traidor" a la patria, y que el hecho no quedara impune con intervenciones diplomáticas. Este cuestionamiento a la diplomacia argentina se debía al posicionamiento que adoptó la Junta Militar ante la aceptación de la propuesta papal de 1980, que no colmaba la expectativa de la revista, tal como expresó en una editorial:

\footnotetext{
"No escapa así a la generalidad que un gobierno de facto tiene la plenipotencialidad de sus actos. Pero sin censurar el haber supeditado el diferendo limítrofe con un país vecino a su Santidad Juan Pablo II, vemos hoy que esa situación ha creado el compromiso de acatar lo que no todos los argentinos comparten, cual es la libertad de los cartógrafos chilenos detenidos en la ejecución de marcaciones limítrofes dentro de nuestro territorio". ${ }^{31}$
}

En mayo de 1981 Cono Sur expresaba su desencanto ante la tercera devaluación en lo que iba del año que aumentaba "un generalizado recelo entre quienes depositaran su confianza en el Proceso de Reorganización Nacional". Tanto en el terreno económico como en el ámbito diplomático, la Junta Militar comenzaba a evidenciar serios problemas que contribuían a acrecentar todo tipo de dudas: "Lo que la nación invirtió en armamentos, vidas y luchas, no puede terminar inútilmente, volviendo a indigencias e inseguridades que sirvan como caldo de cultivo al implacable azote de la subversión". Para inicios de 1982 la inflación descontrolada, la reorganización del

30 Cono Sur, Comodoro Rivadavia, 31/07/1981, p. 4.

31 Cono Sur, Comodoro Rivadavia, 01/05/1981, p. 3. 


\section{“¿Sabe una cosa don Videla?” Construcción de consenso, acción cívica y nacionalismo territorial en la revista Cono Sur, 1978-1982}

frente político y sindical reclamando normalización institucional y mejora de la situación socioeconómica, agotado ya el discurso de la amenaza "subversiva" y con un plan económico que sólo satisfacía a un reducido grupo de empresarios, fueron los principales factores que llevaron a la Junta Militar a pensar en la posibilidad de reconquistar las Islas Malvinas. En este sentido Paula Canelo ha sostenido que "el régimen requería la construcción de un enemigo lo suficientemente poderoso como para justificar una nueva cruzada nacional que le permitiera encubrir sus cada vez más evidentes debilidades" (2006: 71). Al respecto, ya desde 1980 la revista hacía referencia al tema Malvinas en su editorial, dando cuenta de las diversas presentaciones en los foros internacionales reclamando de manera enérgica por la recuperación de las islas. Allí se sostenía que

\footnotetext{
"hace ya tiempo también que el afán de librar esta otra batalla que falta de la guerra de independencia, convoca en voz alta o baja a los argentinos de los estratos sociales más diversos, que no quieren quedarse en las meras palabras o en la pasividad" 32 .
}

Esa "otra batalla de la guerra de independencia que había que librar" era un horizonte demarcado que anclaba en aquella historia argentina que señalaba su mito de origen en el territorio del Virreinato del Río de la Plata, para construir a partir de allí un relato de sucesivas pérdidas y desmembramientos (Lois, 2012). La nota concluía afirmando que el viejo imperio británico ya no era el mismo, y que inclusive estaba en pleno repliegue, dejando un vacío geopolítico que podía ser aprovechado por otras potencias. En 1981 se publicaba una extensa nota titulada "Debemos 'invadir' las islas Malvinas"33, donde se alertaba acerca del profundo desconocimiento de aquel territorio, instando a medidas que fomentaran una mayor concientización. Ese momento tan preanunciado llegó finalmente el 2 de abril de 1982:

\footnotetext{
"debemos felicitarnos que desde hace tiempo haya existido a nivel nacional una campaña de esclarecimiento en torno al problema, por la cual los argentinos fueron concientizados y preparados para el momento actualmente vivido. Gracias a ella es que el pueblo se solidarizó a partir del pasado 2 de abril, salvando diferencias que hasta pocos días antes parecían insalvables, y ese clamor está pesando en el orden internacional para revertir algunas posiciones tomadas por estimación apresurada" 34 .
}

En esa supuesta toma de conciencia y preparación, sin dudas Cono Sur había colaborado bastante con cada una de las crónicas periodísticas, invitando a través de diversos modos de interpelación a que la población participara activamente en el logro de los objetivos planteados por el régimen militar.

\footnotetext{
${ }^{32}$ Cono Sur, Comodoro Rivadavia, 01/06/1980, p. 5.

${ }^{33}$ Cono Sur, Comodoro Rivadavia, 01/03/1981, p. 10.

${ }^{34}$ Cono Sur, Comodoro Rivadavia, 20/04/1982, p. 5.
} 


\section{Gabriel Carrizo}

\section{Conclusiones}

Sin dudas que como han señalado algunos autores, estudios como el que aquí hemos presentado no alcanzan a satisfacer un conocimiento cabal de la efectividad de ese consenso social que se buscaba construir. A sabiendas de que todavía desconocemos el grado de aceptación de ese consenso elaborado "desde arriba", pudimos acercarnos a conocer algunos aspectos del proceso de organización del mismo.

Hemos visto que en forma paralela a la reorganización en Chubut de la burocracia represiva en pos de expulsar a los chilenos considerados ilegales en el contexto del conflicto por el canal del Beagle, se publicaba desde Comodoro Rivadavia una revista que por sus características podemos considerarla inédita para el campo periodístico local. Es decir que, de manera simultánea a la coerción, Cono Sur era el medio de comunicación de las diversas acciones militares que se desarrollaban en la Patagonia buscando el consenso, dado que sus páginas estaban pobladas de referencias de actividades que iban desde ejercicios militares en la frontera hasta el servicio de chocolate brindado por los soldados a niños de Puerto Deseado.

Cono Sur emergió en el campo periodístico local en los años de mayor profundización de la propaganda dictatorial, contribuyendo a la construcción de una imagen venerable de las Fuerzas Armadas. Sin dudas las narraciones periodísticas contenidas en la revista eran vertidas en un campo fértil conformado por lectores que habían experimentado los beneficios tangibles (sobre todo en diversas obras públicas) de administraciones militares de antaño. También la revista surgió en un momento previo al comienzo de la erosión de la legitimidad inicial con que contaba la dictadura. Al poco tiempo comenzaría a evidenciarse la crisis interna de la Junta Militar, las denuncias por violaciones a los derechos humanos que repercutían con fuerza en el exterior, y una crisis económica que empezaría a mostrarse irreversible. Cono Sur no solamente sentó su adhesión al régimen desde una mirada patagónica sino que además le dio peso a la voz militar. Mostró la estrecha colaboración entre civiles y militares, reflejada siempre a través de la cobertura periodística trabajando en las distintas comunidades, sin divisiones en la concreción de obras "históricamente atrasadas" a causa de la mezquindad de la política partidaria. En esa heterogeneidad de comportamientos y actitudes sociales de la sociedad argentina frente a la dictadura, podemos establecer que Cono Sur fue un medio de comunicación que expresó un consenso activo, y desde ese lugar de adhesión se posicionó de una manera tal que podía establecer inclusive sus demandas al régimen. 


\section{“¿Sabe una cosa don Videla?” Construcción de consenso, acción cívica y nacionalismo territorial en la revista Cono Sur, 1978-1982}

\section{Bibliografía}

Águila, G. (2015). Violencia política, represión y actitudes sociales en la historia argentina reciente", En P. Folguera, J. C. Pereira Castañares y otros (coord.), Pensar con la Historia desde el siglo XXI. XII Congreso de la Asociación de Historia Contemporánea, Universidad Autónoma de Madrid.

Águila, G. (2019). El régimen militar entre la represión y el consenso. Intendencia del Capitán Cristiani y las asociaciones vecinales, Rosario, 1976-1981. Anuario IEHS, 34 (1).

Aravena Hermosilla, G. (2009). Nacionalismo y memorias de una guerra que no fue. Patagonia, 1978. Ponencia presentada en el IX Encuentro Nacional y III Congreso Internacional de Historia Oral de la República Argentina, Buenos Aires.

Azcoitia, A. (2014). El Diario Río Negro y la representación de 'lo chileno' durante el conflicto del Beagle (1977 - 1978). ReHiMe, Red de Historia de los Medios (7).

Baeza, B. (2007). Cruzar la frontera en los '70. Chilenos en Comodoro Rivadavia. En B. Baeza, E. Crespo \& G. Carrizo (comps.); Comodoro Rivadavia a través del siglo XX. Nuevas miradas, nuevos actores, nuevas problemáticas. Comodoro Rivadavia: Fondo Editorial.

Baeza, B. (2009). Fronteras e identidades en Patagonia central (1885-2007). Rosario: Prohistoria.

Barros, S. (2019). Comodoro ciudad redonda. En J. M. Paredes (comp.); Comodoro Rivadavia y la catástrofe de 2017. Visiones múltiples para una ciudad en riesgo. Comodoro Rivadavia: Editorial de la Universidad Nacional de la Patagonia San Juan Bosco.

Bayón. C. N. (2012). Construcción discursiva de la revista Cono Sur en relación a los inmigrantes en Patagonia. (Tesis de Licenciatura en Comunicación Social inédita). Universidad Nacional de la Patagonia San Juan Bosco, Comodoro Rivadavia.

Bohoslavsky, E. (2006). Territorio y nacionalismo en Argentina, 1880-1980: del espacio al cuerpo nacional. Ponencia presentada en el Encuentro de Latinoamericanistas Españoles, Santander.

Borrelli, M. (2011). Voces y silencios: la prensa argentina durante la dictadura militar (1976-1983). Perspectivas de la Comunicación (4) nº 1.

Calvo Vicente, C. (1995). El concepto de consenso y su aplicación al estudio del régimen franquista. Spagna contemporánea (7). 


\section{Gabriel Carrizo}

Canelo, P. (2006). La descomposición del poder militar en la Argentina. Las Fuerzas Armadas durante las presidencias de Galtieri, Bignone y Alfonsín (1981-1987). En A. Pucciarelli (coord.); Los años de Alfonsín iel poder de la democracia o la democracia del poder? Buenos Aires: Siglo XXI.

Canelo, P. (2016). La política secreta de la última dictadura argentina (1976-1983). Buenos Aires: Edhasa.

Carrizo, G. (2013). "Entrenar el cuerpo para las grandes fatigas". Acerca de los discursos de educación corporal durante la Gobernación Militar de Comodoro Rivadavia, 1944 - 1955. Revista Estudios del ISHiR (3) nº 5.

Carrizo, G. (2016). Petróleo, peronismo y sindicalismo. La historia de los trabajadores de YPF en la Patagonia, 1944 - 1955. Buenos Aires: Editorial Prometeo.

Carrizo, G. (2019a). Prensa y transición democrática en Comodoro Rivadavia. La revista Cono Sur ante la apertura democrática (1979 - 1983). En F. Camino Vela, G. Carrizo \& M. Moroni (coordinadores); Las transiciones a la democracia en sus actores. Reflexiones desde la Patagonia. Rosario: Prohistoria.

Carrizo, G. (2019b). De salesiana a nacional: los orígenes de la Universidad Nacional de la Patagonia San Juan Bosco. En M. Casarin (coord.); Universidad, producción del conocimiento e inclusión social: a 100 años de la Reforma. Córdoba: Editorial CEA.

Catoira, M. (2018). Dictadura y sociedad en General Sarmiento: entre la coerción y la búsqueda de consenso (1976-1983). En F. Levín (comps.); Tramas del pasado reciente argentino. Historia, memoria y transmisión. Los Polvorines: Universidad Nacional de General Sarmiento.

Cecchetto, G. (2016). Releyendo el ideal civilizatorio del siglo XIX. Relato heroico, colonialismo interno y dictadura militar en Argentina (1976-1983). Ponencia presentada en el XIV Coloquio Internacional de Geocrítica, Barcelona.

Corradi, J. E. (1996). El método de destrucción. El terror en la Argentina. En H. Quiroga \& C. Tcach (comps.). A veinte años del golpe. Con memoria democrática. Rosario: Editorial Homo Sapiens.

Divinzenso, M. A. (2016). La transformación de las relaciones cívico-militares: la 'Acción Cívica' del Ejército (1960-1983). En G. Águila, S. Garaño \& P. Scatizza, (coord.). Represión estatal y violencia paraestatal en la historia reciente argentina: Nuevos abordajes a 40 años del golpe de Estado. La Plata: Universidad Nacional de La Plata. Facultad de Humanidades y Ciencias de la Educación. (Estudios/Investigaciones; 57) Disponible en: http://www.libros.fahce.unlp.edu.ar/index.php/libros/catalog/book/63; 


\section{“¿Sabe una cosa don Videla?” Construcción de consenso, acción cívica y nacionalismo territorial en la revista Cono Sur, 1978-1982}

Divinzenso, M. A. (2017). La 'Acción Cívica' del Ejército argentino: características, modalidades y planificación de una estrategia de legitimación, 1966 - 1975. Páginas (9) $n^{\circ} 19$.

Franco, M. (2002). La 'campaña antiargentina': la prensa, el discurso militar y la construcción de consenso. En J. Casali de Babot \& M. V. Grillo (eds.); Derecha, fascismo y antifascismo en Europa y Argentina. Tucumán: Universidad Nacional de Tucumán.

Gallegos, E. (1971). Invasión por el sur. Comodoro Rivadavia: Editorial Sur.

González Canosa, M. (2011). Consenso y dictadura. Consideraciones analíticas a partir de un legajo policial sobre un conflicto en la ciudad de Lincoln (provincia de Buenos Aires) durante la última dictadura militar argentina. Naveg@mérica (7).

Guglialmelli, J. E. (1980). Cuestión del Beagle. Negociación directa o diálogo de armas. En J. E Guglialmelli y otros; El conflicto del Beagle. Buenos Aires: El Cid Editor.

Iturralde, M. (2017). El terrorismo de estado en noticias. Las operación de 'acción psicológica' en Clarín durante los primeros años de la dictadura. Pasado Abierto. Revista del CEHis (5).

Lacoste, P. (2001). La prensa argentina y el conflicto del Beagle (1977-1978). Revista de Historia y Geografía (15).

Lacoste, P. (2003). La imagen del otro en las relaciones de la Argentina y Chile (15342000). Buenos Aires: Fondo de Cultura Económica.

Lois, C. (2012). La patria es una e indivisible'. Los modos de narrar la historia territorial de la Argentina. Terra Brasilis (1).

Lorenz, F. (2010). Otras marcas. Guerra y memoria en una localidad del sur argentino (1978-1982). En Ernesto Bohoslavsky, Marina Franco, Mariana Iglesias \& Daniel Lvovich (comps.); Problemas de historia reciente del Cono Sur. Vol. II. Buenos Aires: Prometeo.

Luciani, L. (2009). Actitudes y comportamientos sociales durante la última dictadura militar en Argentina (1976-1983). Algunas consideraciones respecto de cómo analizar la compleja trama entre régimen y sociedad. Naveg@mérica (3).

Lvovich, D. (2007). Historia reciente de pasados traumáticos. De los fascismos y colaboracionismos europeos a la historia de la última dictadura argentina. En F. Levín \& M. Franco (comp.); Historia reciente: perspectivas y desafíos para un campo en construcción. Buenos Aires: Paidós. 


\section{Gabriel Carrizo}

Lvovich, D. (2018). Actitudes sociales bajo la última dictadura militar: un análisis crítico de la producción historiográfica. En G. Águila, L. Luciani, L. Seminara \& C. Viano (comps.); La Historia reciente en Argentina. Balances de una historiografía pionera en América Latina. Buenos Aires: Imago Mundi.

Máspoli, E. (2014). Legitimación, discurso y valoración del accionar de las fuerzas armadas durante la última dictadura militar argentina. Un estudio desde la mirada de un periódico local: La Verdad de Junín, 1976. Perspectivas de la Comunicación (7) $\mathrm{n}^{\circ} 1$.

Olivares, M. L. (2015). Entre el triunfalismo y la moderación. Los diarios Crónica y El Patagónico de Comodoro Rivadavia durante la guerra de Malvinas. Páginas (7) nº 13.

Risler, J. \& Shenquer, L. (2019). Guerra, diplomacia y producción de consenso: el plan de acción psicológica del Ejército argentino en el marco del conflicto con Chile por el Canal de Beagle (1981-1982). Revista de Historia Militar (8) nº 17.

Risler, J. (2018). La acción psicológica. Dictadura, inteligencia y gobierno de las emociones, 1955-1981. Buenos Aires: Tinta Limón.

Rodríguez, L. G. (2010). Políticas educativas y culturales durante la última dictadura militar en Argentina (1976-1983). La frontera como problema. Revista Mexicana de Investigación Educativa (15) nº 47.

Rodríguez, L. G. (2014). La noción de frontera en el pensamiento geográfico de 1970 y 1980 en Argentina. Cuadernos de Geografía (23) nº 2.

Rodríguez, L. G. (2015). Universidad, peronismo y dictadura, 1973-1983. Buenos Aires: Prometeo.

Roldán, D. (2007). La espontaneidad regulada. Fútbol, autoritarismo y nación en Argentina '78. Una mirada desde los márgenes. Prohistoria (XI) nº 11.

Seitz, A. I. (2015). Actitudes y comportamientos sociales en regímenes dictatoriales. Aportes para una reflexión metodológica. En S. Jensen, A. Pasquaré \& L. A. Di Gresia (eds.); Fuentes y archivos para una nueva Historia socio - cultural. Bahía Blanca: Hemisferio Derecho.

Shenquer, L. \& Cañada, L. (2020). Monumentos, marcas y homenajes: la última dictadura, los usos del pasado y la construcción de narrativas autolegitimantes (Buenos Aires, 1979-1980). Quinto Sol (24) nº 2.

Torres, S. (2008/2009). Un viaje de idas y vueltas. Imágenes y prejuicios en la construcción de las identidades chilenas en Comodoro Rivadavia. Hermeneutic (8). 


\section{“¿Sabe una cosa don Videla?” Construcción de consenso, acción cívica y nacionalismo territorial en la revista Cono Sur, 1978-1982}

Vázquez, L. (2019). Boom petrolero, crecimiento demográfico y expansión urbana en Comodoro Rivadavia (1958-1963). Pilquen (22) $\mathrm{n}^{\circ} 4$.

Vicente, M. (2018). La familia católica en Comodoro Rivadavia. Tensiones alrededor de la educación entre el fin del primer peronismo y la Revolución Libertadora (1951 1958) (Tesis de Licenciatura en Historia inédita). Universidad Nacional de la Patagonia San Juan Bosco, Comodoro Rivadavia.

Zapata, A. B. (2018). Acción cívica y prensa en la última dictadura. 'Operativos Solidaridad' y la búsqueda de consenso en Bahía Blanca. Question (1) n 58.

Recibido: $26 / 05 / 2020$

Evaluado: $23 / 07 / 2020$

Versión Final: 27/07/2020 